\title{
Environmental Factors and the Risk of Type 1 Diabetes Mellitus-A Case-Control Study
}

\author{
Basma Abdelmoez Ali ${ }^{1 *}$, Mostafa Ahmed Elfoly ${ }^{1}$, Eman Ramadan Ghazawy ${ }^{2}$ and Rania Rashad Bersom ${ }^{1}$ \\ ${ }^{1}$ Pediatric Department, Faculty of Medicine, Minia University, Egypt \\ ${ }^{2}$ Public Health Department, Faculty of Medicine, Minia University, Egypt \\ *Corresponding author: Basma Abdelmoez Ali, Pediatric Department, Faculty of Medicine, Minia University, Egypt, Tel: 8659622215; E-mail: \\ basmaelmoez@yahoo.com
}

Received date: January 15, 2016; Accepted date: February 09, 2017; Published date: February 15, 2017

Copyright: ( $) 2017$ Abdelmoez BA, et al. This is an open-access article distributed under the terms of the Creative Commons Attribution License, which permits unrestricted use, distribution, and reproduction in any medium, provided the original author and source are credited.

\begin{abstract}
Introduction: An interaction between genetic susceptibility and environmental factors is assumed to be elaborate in the etiology of type 1 diabetes mellitus (T1DM). Autoimmunity may be induced in first years of life, suggesting that environmental agents encountered early in life could be triggers of the disease process.

Aim: The aim of the study was therefore to investigate the associations of T1DM with several environmental factors.

Methods: A case-control study was conducted in Minia University Maternity and Children Hospital, Minia governorate, Egypt. One hundred and ten children aged from 2-16 years old who were diagnosed with T1DM and 110 age and sex-matched controls were included. Data regarding environmental factors during gestation, neonatal period, and early years of life were collected by a structured questionnaire. Results: On multivariable logistic regression analysis, maternal age $>35$ years at delivery, the presence of gestational diabetes, pre-eclampsia and taking medications during pregnancy were significantly associated with the occurrence of T1DM. Also, viral infection in early life, low birth weight children ( $<2500$ grams) and those who suffered from neonatal diseases (respiratory distress, jaundice, and infection) were 4.71 and 2.17 folds increased therisk of T1DM. Consumption of cow's milk during the1st year of life was a significant predictor for developing T1DM with OR 3.83 (1.64-8.96), However, vitamin $\mathrm{D}$ supplement and increased duration of breast feeding were significant protective factors.
\end{abstract}

Conclusion: in the present study, certain environmental risk factors were associated with the development of T1DM.

Keywords: Environmental factors; Type 1 Diabetes mellitus

\section{Introduction}

There is an increase in the incidence of T1DM worldwide; annually the overall increase is around $3 \%$, as estimated from data of large epidemiological studies. There are about 78,000 children below the age fifteen develop T1DM worldwide [1].

The universal geographic variation in the incidence of T1DM can almost not be explained by genetic factors alone. The role of environmental factors in the development of T1DM was confirmed by many studies [2-4]. They play a role in the pathogenesis of T1DM as initiators of pancreatic $\beta$-cells destruction [5].

However, controversy still exists to which factors may be responsible for the disease's susceptibility and their variability between different populations.

Egypt accounts for about a quarter of childhood T1DM cases, which considered the largest contribution to the total number of estimated cases in Eastern Mediterranean and Middle Eastern countries [6].

The aim of disease prediction is disease prevention. Prevention of T1DM could be achieved by avoiding those environmental factors which cause the disease or modifying the destructive process before the onset of clinical diabetes [7].

A case-control study was therefore designed to investigate the associations of T1DM with several maternal, neonatal and environmental risk factors in Minia governorate, Upper Egypt, for a better understanding of the risk factors as well as to plan future strategies to control this disease.

\section{Subjects and methods}

This study was conducted in Minia University Maternity and Children Hospital, Minia governorate, Egypt, during the period from March to September 2016.

Inclusion criteria: 110 children (2-16) years old who diagnosed with T1D according to standard American Diabetes Association criteria and had follow up in the pediatrics' endocrinology outpatients 'clinic. The sample size was determined by the availability of patients and time span of the study.

Exclusion criteria: children who came with relatives other than their mothers.

For each case, one age and sex matched control was randomly selected from children consulting the pediatrics' outpatients' clinic 
ward for minor illnesses or accompanying their parents during the visit.

Data were collected using a structured questionnaire designed to meet the objective of this study that inquired about some environmental factors to which cases and controls may have been exposed during gestation, the neonatal period, and early years of life. Mothers of the affected children and those of the control were interviewed to fill in the questionnaire.

\section{Statistical analysis}

Data entry and analysis were all done with IBM compatible computer using software called Statistical Package for Social Science (SPSS) for windows version 19. Graphics were done using Excel. Quantitative data were presented by mean and standard deviation, while qualitative data were presented by frequency distribution. Multivariate logistic regression analysis, Chi Square, and T test were done. The probability of less than 0.05 was used as a cut off point for all significant tests.

\section{Ethical consideration}

Ethical approval was granted by the ethical committee of the Faculty of Medicine, Minia University. Prior to data collection, informed consents were obtained from parents of all children after supplying comprehensive information about the nature of the study.

\section{Results}

\begin{tabular}{|l|l|l|l|}
\hline Risk factor & Cases & $\begin{array}{l}\text { Control } \\
(\mathbf{n}=110)\end{array}$ & P-value \\
\hline & $(\mathrm{n}=110)$ & No (\%) & \\
\hline Maternal age (years) & No (\%) & & \\
\hline$<35$ & $92(83.6)$ & $103(93.6)$ & $0.03^{*}$ \\
\hline$\geq 35$ & $18(16.4)$ & $7(6.4)$ & \\
\hline Pre-eclampsia & & & \\
\hline Negative & $95(86.4)$ & $106(96.4)$ & $0.02^{*}$ \\
\hline Positive & $15(13.6)$ & $4(3.6)$ & \\
\hline Gestational Diabetes Mellitus & & & \\
\hline Negative & $91(82.7)$ & $103(93.6)$ & $0.02^{*}$ \\
\hline Positive & $19(17.3)$ & $7(6.4)$ & \\
\hline History of medication & & & \\
\hline Negative & $45(40.9)$ & $74(67.3)$ & $0.0001^{*}$ \\
\hline Positive & $65(59.1)$ & $36(32.7)$ & \\
\hline$\# *$ Significant & & & \\
\hline
\end{tabular}

Table 1: Comparison between the children with diabetes and the control group as regard potential risk factors during pregnancy.

One hundred and ten children with T1DM were included in the present study, $47(42.7 \%)$ males and $63(57.3 \%)$ females, with a mean age of $10.47 \pm 3.8$ years. For each case, one control subject, matched for both age and sex, was selected.

The mean age of diagnosis of T1DM among children with diabetes was $(6.16 \pm 3.6)$. There were insignificant differences between cases and controls as regard history of consanguinity or family history of diabetes.

As regard the potential risk factors during pregnancy of the index child, there was statistically significant difference between cases and controls regarding maternal age where $16.5 \%$ of the mothers of the children with diabetes were $\geq 35$ years old compared to $6.4 \%$ of the control group. The frequency of the mothers of the children with diabetes who suffered from pre-eclampsia or gestational diabetes were significantly higher than normal children $(13.6 \%$ and $7.3 \%$ versus $3.6 \%$ $\$ 6.4 \%)$ respectively. For maternal drug intake during pregnancy, $59.1 \%$ of mothers of the children with diabetes reported a history drug intake (e.g. anti-hypertensive, as well as antibiotics, analgesics and antiemetics) compared to $32.7 \%$ of mothers in the control group, $(\mathrm{p}<0.0001)$ (Table 1).

Concerning the neonatal and childhood risk factors, as regards the route of delivery, there was insignificant difference between the children with diabetes and the control $(p=0.2)$. Children with diabetes had significantly lower birth weight $(<2500$ gram $)$ compared to the control $(41.8 \%$ versus $23.6 \%)$ with $(\mathrm{p}=0.006)$ and about $11 \%$ of them were pre-term compared to $0.9 \%$ of the control $(\mathrm{p}=0.003)$. It was found that there was statistically significant difference concerning the birth order of participant between cases and controls $(\mathrm{p}=0.03)$. For neonatal diseases, there was a significantly higher number of children in the control group (91.8\%) had no history of neonatal diseases, compared with children with diabetes who had history of respiratory distress, jaundice, and infectious diseases, $(p<0.0001)$. Regarding childhood's viral infections; measles, mumps, and varicella were reported significantly in children with diabetes compared to the control group (Table 2).

Regarding feeding habits during the first year of life, it was found that the majority of the children in the control group (98.2\%) were breast fed compared to the children with diabetes (79.1\%), in addition, the mean total duration of breast feeding was significantly higher in cases than controls $(p<0.0001)$. The introduction of weaning foods before the age of 6 months was significantly higher among children with diabetes compared to the control group (58.2\% versus $37.3 \%$ ). Furthermore, early introduction of gluten significantly differed between cases and controls where more than half (58.2\%) of children with diabetes consumed cereals early in life compared to $33.6 \%$ of the control group. More than half of children with diabetes (53.6\%) consumed cow milk during their first year of life compared to $10.9 \%$ of control group, and this difference was statistically significant, $(\mathrm{p}<0.0001)$.Vitamin D supplementation was significantly higher in the control group than children with diabetes during their first year of life $(66.4 \%$ versus $8.2 \%)$ (Table 3$)$.

As shown in (Table 4), the standard method of binary logistic regression was used to assess the effect of the different predictors on the occurrence of T1DM (dependent variable). Concerning the potential risk factors during pregnancy of the index child; mother age, presence of gestational diabetes, pre-eclampsia and taking medications during pregnancy were significantly associated with occurrence of T1DM, OR (95\% CI) were $\{1.93$ (1.37-2.73), 4.16 (1.53-11.28), 3.97 (1.19-13.24) and 3.15 (1.72-5.77)\} respectively. Regarding neonatal and childhood risk factors, it was found that children who caught viral 
infection in early life (measles, mumps, chicken pox), were at increased risk of being diabetic 5 folds higher than others. Moreover low birth weight $(<2500$ grams) children and those who suffered from neonatal diseases (respiratory distress, jaundice, and infection) were 4.71 and 2.17 folds increased risk of T1DM. Consumption of cow's milk during the 1st year of life was a significant predictor for developing T1DM with OR 3.83 (1.64-8.96), However, vitamin D supplement and increased duration of breast feeding were significantly protective factors.

\section{Discussion}

This study revealed that maternal age at delivery was significantly associated with T1DM where five years increase in mother age, increases the risk of T1DM nearly by two folds. This was in accordance with a finding of pooled analysis of 30 previous studies which demonstrated that there was, on average, a $5 \%(95 \%$ CI 2,9$)$ increase in childhood type 1 diabetes odds per 5 -year increase in maternal age $(\mathrm{p}=0.006)$ [8].

The current study revealed a significant association of T1DM with maternal gestational diabetes and pre-eclampsia. Additionally, after adjustment for other factors, it showed that both variables were significant predictors in the development of childhood T1DM, with an $\mathrm{OR}=4.16(1.53-11.28)$ and $3.97(1.19-13.24)$, respectively. Similar results were reported by Stene et al. in Denver [9]. Lee et al. in Taiwan found that the prevalence of gestational diabetes was much higher in mothers of children with diabetes than in control mothers [10]. In contrast, other studies by Algert et al. [11] and Alhonen et al. [12] revealed that gestational diabetes was not significantly associated with T1DM. Algert et al. reported that pre-eclampsia was significantly associated with childhood diabetes, but only among children diagnosed before 3 years of age [11].

For maternal drug intake during pregnancy, it was found that $59.1 \%$ of mothers of the children with diabetes reported a history of antihypertensive intake, as well as antibiotics, analgesics, and antiemetics during pregnancy, and their children were at increased risk to develop T1DM about three folds with an $\mathrm{OR}=3.15$ (1.72-5.77). Majeed et al reported the same results in Basrah, Iraq [13].

Existing data on the probable association between gestational age, birth weight, and T1DM were inconsistent and contradictory. Our data indicated that children who had birth weight $<2500$ grams were at a significantly higher risk of T1DM $(\mathrm{OR}=2.17,95 \% \mathrm{CI}=0.23$ to 0.91$)$ compared with those who had birth weight $\geq 2500$ grams, controversy with Robertson et.al, who didn't find any association between birth weight and risk of T1DM in children under 15 years old in Grampian, Scotland [14]. However, a Swedish study found that children who developed T1DM at 1-15 years of age tended to have a larger for gestational age weight, and such findings were supported in a subsequent meta-analysis [15].

In the current study, it was observed that the child's birth order significantly associated with T1DM as more than half of diabetic children $(52.7 \%)$ were the 3 rd child or more. This was inconsistent with Robertson et al. [14] who found no difference between cases and control as regard the birth order. The difference could be due to the characteristic of Egyptian women, especially in Upper Egypt; she deals carefully with the 1st child, her worrying decline gradually with increased birth order especially regarding the feeding habits. Many studies reported that neonatal respiratory diseases, infections, and jaundice are risk factors for T1DM $[8,16]$. This was confirmed by the current study where neonatal infections, respiratory distress and jaundice were significantly increased the risk to develop T1DM (OR= $4.71,95 \% \mathrm{CI}=2.02-10.95)$. Also, this result was consistent with another study conducted in Denmark [17].

Furthermore, our study revealed that early childhood infections (measles, mumps, and varicella) were significantly associated with T1DM. Similar findings were reported by Snell-Bergeon et al. [18]. Both specific childhood viral infections and a low overall infection load in childhood (hygiene hypothesis) had been proposed as possible environmental determinants of T1DM. Ramondetti et al. [19] reported a significant association between history of mumps and T1DM, while in the same study there was insignificant difference between the incidence of measles infection and T1DM.

Early nutrition clearly represents one of the first environmental determinants to which an infant is exposed. In the current study while we observed introduction of weaning foods before the age of 6 months was significantly associated with T1DM on univariable analysis, such an effect was not found in the multivariable model and it was found that longer duration of breast feeding was associated with protection against T1DM with OR (95\% CI) 0.86 (0.81-0.92). This was in accordance with Ahadi et al. [20] in Iran and Holmberg et al. [21] in Sweden who concluded that breast feeding modifies the risk of beta cells autoimmunity even years after finishing breast feeding. Moreover, Alves et al. [22] found that a short breast feeding period (less than 4 months) may contribute to T1DM.

Moreover, it was noticed that consumption of cow milk during the1st year of life increases the odds of developing T1DM OR (95\% CI) 3.83 (1.64-8.96). Similar results were reported by Goldfarb [23] who suggested that Cow's milk products are associated with the onset of T1D. Also, this finding was in agreement with Megeid et al. in Saudi Arabia [24], who found an association between T1DM and prolonged consumption of cow's milk $(\mathrm{OR}=4.3)$ and short duration of breastfeeding $(\mathrm{OR}=3.5)$. It was, therefore, possible that the introduction of foreign proteins in early infancy, when the maturation of the gut immune system is not complete, is someway harmful and predisposes to $\beta$-cell autoimmunity [25].

Exposure to wheat gluten had also been associated with the emergence of b-cell autoimmunity in children [26,27]. In the current study, the children with diabetes had a significant higher frequency of early introduction of gluten containing food where $(p=0.0004)$. This was in agreement with Beyerlein et al. [28].

Vitamin D supplementation during infancy was inversely associated with the risk of type 1 diabetes OR (95\% CI) 0.033 (0.01-0.09), this was in agreement with Hypponen et al. [29] who found a strong dose dependent, protective effect of vitamin $\mathrm{D}$ supplementation. It was believed that vitamin $\mathrm{D}$ might somehow inhibit the autoimmune reaction targeted towards the $\beta$ cells of the pancreas. Furthermore, low level of vitamin D in infancy may lead to impairment of immune system functioning, which could have long-term effects on immune responses later in life [30]. In conclusion, there were many environmental factors which may play a significant role in precipitation of T1DM among children, those factors are; gestational diabetes, pre-eclampsia, maternal medication, early neonatal illness (RDS and prematurity) short duration of breast feeding, early introduction of cow milk and gluten, lack of vitamin D supplementation, early childhood viral infection. Identification of such factors is crucial and might play a role in lowering the risk of developing the disease. 
Citation: Abdelmoez BA, Elfoly MA, Ghazawy ER, Bersom RR (2017) Environmental Factors and the Risk of Type 1 Diabetes Mellitus-A Case-

Page 4 of 6

\section{Limitations of the study}

\begin{tabular}{|c|c|c|c|}
\hline Risk factor & Cases & Control $(n=110)$ & P-value \\
\hline & $(n=110)$ & No (\%) & \\
\hline Mode of delivery & No $(\%)$ & & \\
\hline Normal & $76(69.1)$ & $85(77.3)$ & 0.2 \\
\hline Cesarean section & $34(30.9)$ & $25(22.7)$ & \\
\hline \multicolumn{4}{|l|}{ Maturity } \\
\hline Full term & $98(89.1)$ & $109(99.1)$ & $0.003^{*}$ \\
\hline Pre term & $12(10.9)$ & $1(0.9)$ & \\
\hline \multicolumn{4}{|l|}{$\begin{array}{l}\text { Child birth weight } \\
\text { (grams) }\end{array}$} \\
\hline$<2500$ gram & $46(41.8)$ & $26(23.6)$ & $0.006^{*}$ \\
\hline$\geq 2500$ gram & $64(58.2)$ & $84(76.4)$ & \\
\hline \multicolumn{4}{|l|}{ Child birth order } \\
\hline $1 \mathrm{st}$ & $27(24.5)$ & $43(39.1)$ & $0.03^{*}$ \\
\hline $2 n d$ & $25(22.7)$ & $26(23.6)$ & \\
\hline $3 r d+$ & $58(52.7)$ & $41(37.3)$ & \\
\hline \multicolumn{4}{|l|}{$\begin{array}{l}\text { History of NICU } \\
\text { admission }\end{array}$} \\
\hline Positive & $45(40.9)$ & $11(10)$ & $0.0001^{*}$ \\
\hline Negative & $65(59.1)$ & $99(90)$ & \\
\hline \multicolumn{4}{|l|}{ Neonatal diseases } \\
\hline Negative & $75(68.2)$ & $101(91.8)$ & $0.0001^{*}$ \\
\hline $\begin{array}{l}\text { Positive (respiratory } \\
\text { distress, jaundice and } \\
\text { infection) }\end{array}$ & $35(31.8)$ & $9(8.2)$ & \\
\hline \multicolumn{4}{|l|}{ Measles } \\
\hline Negative & $94(85.5)$ & $105(95.5)$ & $0.01^{*}$ \\
\hline Positive & $16(14.5)$ & $5(4.5)$ & \\
\hline \multicolumn{4}{|l|}{ Mumps } \\
\hline Negative & $98(89.1)$ & $107(97.3)$ & $0.02^{*}$ \\
\hline Positive & $12(10.9)$ & $3(2.7)$ & \\
\hline \multicolumn{4}{|l|}{ Varicella } \\
\hline Negative & $86(78.2)$ & $101(91.8)$ & $0.005^{*}$ \\
\hline Positive & $24(21.8)$ & $9(8.2)$ & \\
\hline
\end{tabular}

Table 2: Comparison between the children with diabetes and the control group as regard potential neonatal and childhood risk factors.
We developed a structured questionnaire due to unavailability of hospital records:

We were unable to comprehensively take all potential environmental and perinatal/neonatal risk factors into account.

We tried to minimize recall bias so many cases were excluded from the study because of inability of their mothers to remember some events.

\begin{tabular}{|c|c|c|c|}
\hline Risk factor & Cases & Control & P-value \\
\hline & $(n=110)$ & $(n=110)$ & \\
\hline & No (\%) & No (\%) & \\
\hline \multicolumn{4}{|l|}{ Feeding pattern } \\
\hline Bottle fed & $23(20.9)$ & $2(1.8)$ & $0.0001^{*}$ \\
\hline Breast fed & $87(79.1)$ & $108(98.2)$ & \\
\hline \multirow[t]{2}{*}{$\begin{array}{l}\text { Duration of breast feeding\# } \\
\text { (months) }\end{array}$} & 24-Apr & 24-Aug & \\
\hline & $14.38 \pm 8.9$ & $19.69 \pm 5.3$ & $0.0001^{*}$ \\
\hline \multicolumn{4}{|l|}{$\begin{array}{l}\text { Time of introduction of } \\
\text { weaning foods }\end{array}$} \\
\hline \multicolumn{4}{|l|}{$\leq 6$ months } \\
\hline \multirow[t]{2}{*}{$>6$ months } & $64(58.2)$ & $41(37.3)$ & $0.003^{*}$ \\
\hline & $46(41.8)$ & $69(62.7)$ & \\
\hline \multicolumn{4}{|l|}{$\begin{array}{l}\text { Early introduction of cereals } \\
\text { (gluten) }\end{array}$} \\
\hline Positive & $64(58.2)$ & $37(33.6)$ & $0.0004^{*}$ \\
\hline Negative & $46(41.8)$ & $73(66.4)$ & \\
\hline \multicolumn{4}{|l|}{$\begin{array}{l}\text { Cow milk consumption during } \\
\text { 1st year of life }\end{array}$} \\
\hline \multicolumn{4}{|l|}{ Positive } \\
\hline \multirow[t]{2}{*}{ Negative } & $59(53.6)$ & $12(10.9)$ & $0.0001^{*}$ \\
\hline & $51(46.4)$ & $98(89.1)$ & \\
\hline \multicolumn{4}{|l|}{ Vitamin D supplement } \\
\hline Positive & $9(8.2)$ & $73(66.4)$ & $0.0001^{*}$ \\
\hline Negative & $101(91.8)$ & 37 (33.6) & \\
\hline
\end{tabular}

Table 3: Comparison between the children with diabetes and the control group as regard nutritional risk factors. 


\begin{tabular}{|l|l|l|}
\hline Potential risk factors during pregnancy of the index child & $1.93(1.37-2.73)$ & 0.0001 \\
Mother age & $4.16(1.53-11.28)$ & 0.005 \\
Presence of gestational DM & $3.97(1.19-13.24)$ & 0.025 \\
Presence of pre-eclampsia & $3.15(1.72-5.77)$ & 0.0001 \\
Taking medication & & 0.02 \\
\hline Potential neonatal and childhood risk factors & $2.17(0.23-0.91)$ & 0.0001 \\
Low birth weight (<2500 gram) & $5.08(2.56-10.09)$ & 0.0001 \\
Diseases in early life (measles, mumps, varicella) & $4.71(2.02-10.95)$ & \\
Neonatal diseases (respiratory distress, jaundice and infection) & & 0.002 \\
\hline Nutritional risk factors & $3.83(1.64-8.96)$ & 0.0001 \\
Cow milk consumption during 1st year of life & $0.033(0.01-0.09)$ & 0.0001 \\
Vitamin D supplement & $0.86(0.81-0.92)$ & \\
Increased duration of breastfeeding & & \\
\hline
\end{tabular}

Table 4: Multivariable logistic regression analysis of factors independently associated with T1DM.

\section{References}

1. International Diabetes Federation (2011) The IDF Diabetes Atlas. 5th edn, Brussels: International Diabetes Federation 5: 20.

2. Dahlquist G (1994) Non-genetic risk determinants of type 1 diabetes. DiabeteMetab 20: 251-257.

3. Vlajinac H, Sipetic S, Marinkovic J, Bjekic M, Kocev N, et al. (2006) The Belgrade childhood diabetes study-comparison of children with type 1 diabetes with their siblings. Paediatric Perinat Epidemiol 20: 238-2436.

4. Karvonen M, Viik-Kajander M, Moltchanova E, Libman I, LaPorteRv, et al. (2000) Incidence of childhood type 1 diabetes worldwide. Diabetes Mondiale (DiaMond) Project Group. Diabetes Care 23: 1516-1526.

5. Knip M, Simell O (2012) Environmental Triggers of Type 1 Diabetes. Cold Spring HarbPerspect Med 2:a007690.

6. Soltesz G, Patterson C, Dahlquist G (2006) Global trends in childhoodtype 1 diabetes. In: Diabetes Atlas, 3rd edn. International Diabetes Federation, Brussels 153-190.

7. Leslie R, Ho-Le L, Beyan H (2013) Viruses and Autoimmune Diabetes: A History. Diabetes and Viruses, Springer Science 2: 7-12.

8. Cardwell CR, Stene LC, Joner G, Bulsara M, Cinek A, et al. (2010) Maternal age at birth and childhoodtype 1 diabetes: a pooled analysis of 30 observational studies. Diabetes 59: 486-494.

9. Stene LC, Barriga K, Norris JM, Hoffman M, ErlichHA, et al. (2004) Perinatal factors and development of islet autoimmunity in early childhood: the diabetes autoimmunity study in the young. Am J Epidemiol 160: 3-10.

10. Lee HY, Lu CL, ChenHF, SuHF, Li CY (2015) Perinatal and childhood risk factors for early-onset type 1 diabetes: a population-based casecontrol study in Taiwan. Eur J Public Health 25: 1024-1029.

11. Algert CS, McElduff A, Morris JM, Roberts CL (2009) Perinatal risk factors for early onset of Type 1 diabetes in a 2000-2005 birth cohort. Diabet Med 26:1193-1197.

12. Alhonen S, Korhonen S, Tapanainen P, KnipM, Veijola R (2011) Extended family history of diabetes and autoimmune diseases in children with and without type 1 diabetes. Diabetes Care 34: 115-117.

13. MajeedA, Kadhum M (2011) Risk Factors for Type 1 Diabetes Mellitus among Children and Adolescents in Basrah. Oman J 26:189-195.

14. RobertsonL Harrild K (2010) Maternal and neonatal risk factors for childhood type 1 diabetes: a matched case-control study. BMC Public Health 10: 281R.

15. Cardwell CR, Stene LC, Joner G, Davis EA, Cinek O, et al. (2010) Birth weight and the risk of childhood-onset type 1 diabetes: a meta-analysis of observational studies using individual patient data. Diabetologia 53: 641-651.

16. McKinney P, Parslow R, Gurney K, Law G, Bodansky H, (1999) Perinatal and neonatal determinants of childhood type 1diabetes. A casecontrolstudy in Yorkshire, U.K. Diabetes Care 22: 928-932.

17. Svensson J, Carstensen B, Mortensen HB, Borch-Johnsen K (2005) Danish Study Group of Childhood Diabetes: Early childhood risk factors associated with type 1 diabetes-is gender important? Eur J Epidemiol 20: 429-434.

18. Snell-Bergeon JK, Smith J, Dong F, Barón AE, Barriga K, (2012) Early childhood infections and the risk of islet autoimmunity: the Diabetes Autoimmunity Study in the Young (DAISY). Diabetes Care 35: 2553-2558.

19. Ramondetti F, Sacco S, Comelli M, Bruno G, FalorniA,Iannilli A (2012) Type 1 diabetes and measles, mumps and rubella childhood infections within the Italian Insulin-dependent Diabetes Registry. Diabet Med 29: 761-766.

20. Ahadi M, Tabatabaeiyan M, Moazzami K (2011) Association between environmental factorsand risk of type 1 diabetes- a case-control study. Pol J Endocrinol 62: 134-137.

21. Holmberg H, Wahlberg J, Vaarala O, Ludvigsson J (2007) Short duration of breast-feeding as a risk-factor for beta-cell autoantibodies in 5-year-old children from the general population. Br J Nutr 97: 111-116.

22. Alves JG, Figueiroa JN, Meneses J. Alves GV (2012) Breastfeeding protects against type 1 diabetes mellitus: a case-sibling study. Breastfeed Med 7: 25-28.

23. Goldfarb MF (2008) Relation of time of introduction of cow milk protein to an infant and risk of type-1 diabetes mellitus. J Proteome Res 7: 2165-2167.

24. Megeid FY, Bakeit ZA, Karim BO (2011) Early introduction of cow's milkand short duration of breastfeeding is associated with increasingrisk of juvenile diabetes. World J Med Sci. 6: 54-60.

25. Vaarala $\mathrm{O}$ (2002) The gut immune system and type 1 diabetes. Ann N Y AcadSci 958: 39-46.

26. Norris JM, Barriga K, Klingensmith GH, Hoffman M, Eisenbarth GS, et al. (2003) Timing of initial cereal exposure in infancy and risk of islet autoimmunity. JAMA 290: 1713-1720.

27. Ziegler AG, Schmid S, Huber D, Hummel M, Bonifacio E (2003) Early infant feeding and risk of developing type 1 diabetes-associated autoantibodies. JAMA 290: 1721-1728.

28. Beyerlein A, Chmiel R, Hummel S, Winkler C, Bonifacio E, et al. (2014) Timing of gluten introduction and islet autoimmunity in young children: updated results from the BABYDIET study. Diabetes Care 37: e194-e195. 
Citation: Abdelmoez BA, Elfoly MA, Ghazawy ER, Bersom RR (2017) Environmental Factors and the Risk of Type 1 Diabetes Mellitus-A CaseControl Study. J Diabetes Metab 8: 723. doi:10.4172/2155-6156.1000723

Page 6 of 6

29. Hypponen E, Laara E, Reunanen A, Jarvelin MR, Virtanen SM (2001) Intake of vitamin $\mathrm{D}$ and risk of type 1 diabetes: a birth-cohort study. Lancet 358:1500-1503.
30. Stene LC, Ulriksen J, Magnus P, Joner G (2000) Use of cod liver oil during pregnancy associated with lower risk of type I diabetes in the offspring. Diabetologia 43:1093-1098. 